\title{
Operações enunciativas e predicativas: análise de marcas linguísticas na produção textual por alunos do Ensino Fundamental II
}

DOI: http://dx.doi.org/10.21165/el.v50i3.2884

\author{
Leonildes Pessoa Facundes ${ }^{1}$ \\ Marlene Aparecida Viscardi Mantovani²
}

\section{Resumo}

Este artigo objetiva analisar a construção da moral da fábula Hortifrutigranjeira, realizada por alunos do $6^{\circ}$ ano do ensino fundamental II sob um olhar estritamente enunciativo na perspectiva dos fundamentos teóricos, defendido pela Teoria das Operações Predicativas e Enunciativas (TOPE) proposta pelo linguista Antoine Culioli (1990, 1999). Entre os vários conceitos aqui abordados, centramos a análise no que se refere à modalização. $\mathrm{Na}$ análise das marcas linguísticas identificadas nos textos, buscamos verificar: a) os processos operatórios linguísticos envolvidos na elaboração da moral; b) se o aluno foi capaz de discretizar a narrativa do texto de apoio; c) quais mecanismos enunciativos o aluno envolveu na construção da moral. Consideramos como fundamental a articulação da língua e da linguagem como parâmetro para o ensino de Língua Portuguesa e para o desenvolvimento linguístico-cognitivo do educando.

Palavras-chave: moral; Teoria das Operações Enunciativas e Predicativas; modalização; linguístico-cognitivo; produção textual.

1 Universidade Estadual do Maranhão (UEMA), Maranhão, São Luís, Brasil; leonildespessoa@gmail.com; http://orcid.org/0000-0002-9039-970X

2 Universidade Federal de São Carlos (UFSCar), São Carlos, São Paulo, Brasil; viscardi.marlene@gmail.com; https://orcid.org/0000-0001-5603-1904 


\title{
Enunciative and predicative operations: analysis of linguistic marks in textual production by Elementary School II
}

\begin{abstract}
This article aims to analyze the moral construction of the fable Hortifrutigranjeira, carried out by $6^{\text {th }}$ graders of Elementary school under a strictly enunciative look in the perspective of the theoretical foundations defended by the Theory of Predicative and Enunciative Operations (TOPE) proposed by the linguist Antoine Culioli (1990, 1999). Among the various concepts discussed here, we chose modalization as the focus of the analysis. As for the the linguistic marks identified in the texts, we sought to verify: a) the linguistic operational processes involved in the elaboration of morals; b) if the student was able to discretize the narrative of the supporting text; $c$ ) what enunciative mechanisms the student involved in the construction of morals. We consider the articulation of language and language to be fundamental as a parameter for the teaching of Portuguese Language and for the linguistic-cognitive development of the student.
\end{abstract}

Keywords: Moral; Theory of Predicative and Enunciative Operations; Modalization; Linguistic-cognitive; Text production.

\section{Introdução}

Sabe-se que a moral faz parte das fábulas, situa-se no final desse gênero textual, após a apresentação da narrativa, como se fosse um fechamento ou conclusão. Observamos como professoras que alguns alunos, quando produzem seus textos, mesmo não sendo fábula, querem e colocam como forma de conclusão a conhecida e chamada "moral da história". No momento em que o aluno constrói a moral para finalizar as narrativas, ele coloca em prática sua criatividade, dá sua opinião, ou seja, opera com a língua e reflete sobre seu funcionamento.

O presente artigo tem por objetivo refletir e analisar a produção de uma moral para a fábula Hortifrutigranjeira de Luís Fernando Veríssimo realizada por alunos do $6^{\circ}$ Ano do Ensino Fundamental II. Pautamo-nos no referencial teórico de Culioli que busca a articulação entre língua e linguagem. Para o autor, a língua é um sistema de representação da atividade de linguagem produzida por interlocutores em interação. A linguagem é a atividade significativa representacional, é acessível por meio de sequências do texto, por meio de organização de marcos, traços de operações subjacentes. Nesse processo dialógico, realizam-se as operações de representação mental, de referenciação e de regulação.

O sujeito, no caso, o aluno, constrói o domínio nocional e, com sua criatividade, reflete sobre a própria língua, passando por processos denominados pela Teoria de discreto, de 
compacto e de denso. Culioli (1999b) diz que a linguagem é uma atividade que constrói representações que são referenciadas e reguladas, percebe-se que, na construção da moral presente no enunciado, o educando passa pelo processo de particularização (discreto) para o denso (generalização) para a construção de uma tese (embrião de uma dissertação) que se valida com a verdade, ou, às vezes, se apoia na referência textual e fica na modalização, faz sua apreciação.

O corpus se constitui de 52 textos produzidos por alunos do $6^{\circ}$ ano do Ensino Fundamental II, referente a 2 (duas) salas de aulas, do turno vespertino, da Escola Municipal Luiz Falcão, localizada na Comunidade "Estiva", zona rural da cidade de Caxias-MA. Desses 52 textos, selecionamos 13 para apresentar e analisar neste artigo. A escola citada, em que foi feita a coleta de dados, foi escolhida porque é muito procurada pelos pais devido ao êxito apresentado em relação à apreendizagem.

O artigo foi dividido nas seguintes partes: alguns conceitos teóricos da TOPE que fundamentam a atividade epilinguística da linguagem como eixo central para as questões de Ensino; metodologia utilizada para aplicação e análise de algumas produções (13), referentes à construção da moral da fábula e, por fim, as considerações finais que evidenciam a importância de proporcionar ao aluno o questionamento sobre as operações realizadas na atividade de linguagem.

\section{Conceitos teóricos da TOPE: enunciação, noção e domínio nocional, modalização}

Apresentamos aqui alguns conceitos teóricos da TOPE utilizados durante a pesquisa e análise dos dados coletados.

A enunciação, segundo a teoria Culioliana, é concebida como um processo de constituição de sentido que é construído enunciado por enunciado. Nesta fase de ensino-aprendizagem, se faz necessário o estudo na abordagem léxico-gramatical sobre a atividade da linguagem, possibilitando aos educandos o desenvolvimento de sua criatividade e aos educadores atenção para não repetir modelos. Essa instabilidade instaurada na atividade de linguagem permite ao aluno operar com a língua, assim vai se apropriando dela e criando novas formas de dizer.

Culioli (1990, 1999a) inova quando propõe a TOPE (Teoria das Operações Predicativas e Enunciativas), pois visa apreender o funcionamento da linguagem somente por meio das línguas, dos observáveis que são as produções linguísticas na diversidade das línguas naturais. Onofre (2003) diz que a concepção de linguagem para Culioli é de uma atividade significante em que os enunciados são produtos dinâmicos resultantes da atividade de linguagem, ou seja, a relação entre a produção e reprodução linguísticas geradas pelos enunciadores em suas enunciações. 
Portanto, a enunciação, segundo a TOPE, é concebida como um processo de constituição de sentido que é construído enunciado por enunciado, ou seja, a produção de significação produzida pelos interlocutores em interação. Nesse processo dialógico, realizam-se as operações de representação mental, de referenciação e de regulação.

Sinteticamente, esse processo dialógico funciona dessa maneira: a atividade de representação mental onde ocorre a construção das noções, as experiências do sujeito, é composta por uma sequência de operações que se desenvolvem em diferentes níveis, mediada por fatores físico-culturais e mentais, portanto, é de ordem psicológica.

Já os processos de referenciação vão constituir um sistema referencial intersubjetivo que consiste na localização dos objetos metalinguísticos construídos e reconstruídos, é materialidade linguística, ou seja, o texto, o enunciado. Sua construção é mediada pelo sujeito, por isso, é de ordem sociológica.

E a regulação, de ordem psicossociológica, é o próprio diálogo, definida pela relação enunciativa instaurada entre os sujeitos enunciadores. Segundo Culioli (1999), essa operação é central na atividade de linguagem, pois consiste nos ajustamentos feitos pelos sujeitos na atividade de linguagem. Na regulação que são instauradas relações de alteridade, complexas e formalizáveis entre enunciador e coenunciador. Ela é indissociável das operações de representação e referenciação.

Segundo a Teoria, a atividade de linguagem é significativa, representacional e acessível por meio de marcas, traços de operações subjacentes. Doravante, a TOPE propõe uma análise em que o léxico vai sendo operado a partir de construções de domínios nocionais e de acordo com as experiências individuais de cada sujeito, ele opera, se apropria e cria.

Os conceitos de domínio nocional e de noção se encontram no Centro dos estudos da TOPE e estão ligados ao estado de conhecimento e à atividade de elaboração de experiências de cada indivíduo. Para Culioli (1999a), noção pode ser compreendida como um conjunto de propriedades que dependem de suas combinações, determinadas por fatores fisico-psico-culturais, para formar categorias como objetos ou fenômenos do mundo. Para o autor, a noção se apresenta "aberta" em potencial e tomará forma no processo de predicação desenvolvido pelos sujeitos. O domínio nocional é a amplitude desses traços, a construção de sentido se dá pela relação entre noções não cristalizadas. Temos traços estáveis, mas sempre um sujeito na regulação, portanto deve-se olhar sempre para a enunciação, para o invariável.

A modalidade, segundo Culioli (1999a), pode ser considerada uma operação de determinação e sua função ocorre na confıguração semântica das representações, na construção dos valores referenciais e na localização das posições enunciativas dos 
sujeitos, sendo assim, ela assinala o ponto de vista do enunciador sobre um conteúdo que constrói linguisticamente, evidenciando inclusive o seu posicionamento em relação a um coenunciador.

O sujeito enunciador expõe um conteúdo de pensamento que ele mesmo considera ora como uma verdade, ora como uma hipótese, ora como um questionamento, podendo exprimir uma ordem, uma obrigação ou um desejo.

A modalidade opera sobre dois planos: a) relação do sujeito enunciador com o conteúdo que ele mesmo constrói - relação entre sujeito enunciador e a relação predicativa, aqui ocorre a avaliação das chances de realização da relação predicativa; b) relação do sujeito enunciador com o coenunciador - trata-se da relação intersubjetiva.

Segundo Valentim (2004), a modalização é um dos temas menos tratados nos estudos linguísticos, no domínio da lógica ele é privilegiado. Os valores modais confluem para a determinação de qualquer enunciado, juntamente com os valores temporais-aspectuais, resultando da localização da relação predicativa em relação ao sujeito enunciador ou a uma classe de sujeitos enunciadores.

Valentim (2004, p. 117) diz que "a concepção de modalidade em Culioli ligada fortemente ao conceito decisivo de enunciação é concebida como um processo inserido numa necessidade teórica, não numa prática efetiva". A categoria da modalidade é representada por determinados auxiliares modais, tais como, os advérbios (certamente, provavelmente, maravilhosamente etc. e itens lexicais que exprimem o ponto de vista do sujeito enunciador (importante, triste, inevitável, formidável)); também a complementação verbal (achar, pensar), mais os adverbiais: certamente, felizmente, lamentavelmente, sem dúvida, talvez, segundo Valentim (2004, p. 217), nas construções sintáticas, por exemplo, adjuntos modais: na minha opinião, do meu ponto de vista etc., verbos ditos "auxiliares de modalidade" ou "verbos modais": poder, dever, ter de, parecer...

Em relação à predicação, o sujeito enunciador, em um primeiro momento, ordena os termos e decide qual termo será a origem da relação predicativa, operação de natureza predicativa.

A lexis é considerada pré-modal e pré-assertiva. Ela se reveste de um valor modal mediante operações enunciativas que operam sobre a relação predicativa. Por via dessas operações enunciativas, a enunciação por um sujeito enunciador implica uma modalização. O sujeito enunciador ao construir uma lexis constrói um conjunto fechado de relações intralexicais. 
Na relação intersubjetiva, o sujeito enunciador é considerado o centro organizador do enunciado, remete ao interlocutor por meio do seu dizer e, assim, determina duas modalidades fundamentais: 1) modalização que reflete os modos de dizer, de predicar, onde o sujeito recorre aos índices linguísticos que expressam seus modos de apoio; 2) relação intersubjetiva está em jogo, implicando uma distância em relação ao que é visado; situações de desejo, de vontade, de ordem.

Na questão da modalidade, o sujeito desempenha um papel fundamental, pois ele se inscreve no sistema linguístico como um parâmetro teórico, metalinguístico e isso acarreta o estabelecimento de uma classe de sujeitos, localizados entre si, responsáveis pela construção de valores referenciais da categoria modalidade.

O sujeito, ao instanciar-se como sujeito enunciador pela e na enunciação, determina valores temporais-espaciais, possibilitando a construção de um sistema de referência. O sistema de referência, considerado como um localizador das estruturas abstratas que o sujeito enunciador constrói pela e na enunciação, é consequência e condição de toda a enunciação. A categoria linguística da modalidade é definida graças ao conjunto de processos pelos quais o sujeito localiza uma relação primitiva.

Culioli (1985) considera que as expressões modais apresentam um "nó de valores" e não funcionam de maneira estanque. A modalidade opera sempre em dois planos: relação do enunciador com o conteúdo que ele diz e a relação do enunciador com o coenunciador. Ele propõe uma descrição metalinguística dos valores da categoria de modalidade, em função das operações enunciativas que as suas ocorrências marcam.

Os valores modais com os valores temporais-aspectuais confluem para a determinação de qualquer enunciado e resultam da localização da relação predicativa em relação ao sujeito enunciador ou a uma classe de sujeitos enunciadores. Os verbos modais são sempre seguidos por um infınitivo e não são empregados no imperativo.

Segundo Culioli (1990), a modalidade marca um tipo de relação entre o sujeito e seu enunciado, que, consequentemente, constrói julgamentos. Ela se constrói inicialmente, a partir da representação do sujeito que age sobre o mundo e sobre os outros, dando origem à representação linguística.

Com base nessa relação, Culioli (1990) concebe quatro grupos de operações modais:

\section{- Modalidade 1}

a) Asserção (afirmativa/negativa): o sujeito enunciador dispõe de dois valores, verdadeiro/ falso ou afirmativo/negativo para fazer a opção por um ou outro. É por meio da asserção que o sujeito enunciador indica que o que ele está predicando é ou não fato. 
b) Interrogação: o sujeito enunciador dá ao seu coenunciador a opção de escolher um valor positivo ou negativo $p / \sim p$, ou seja, uma assertiva negativa ou positiva.

c) Injunção (súplica, pedido, sugestão, algo que possa vir verdadeiro ou falso): o sujeito enunciador exerce sobre o coenunciador uma espécie de "pedido, ordem ou sugestão" para que este realize uma ação.

d) Hipotético: a hipótese (positiva ou negativa) é colocada pelo enunciador de uma forma absoluta.

\section{- Modalidade 2: Epistêmica}

Exprime uma ausência de certeza por parte do enunciador quanto à validação da relação predicativa; não se trata do falso ou verdadeiro, como ocorre na asserção, mas de uma avaliação essencialmente quantitativa, oscilando entre o provável, o improvável, o possível, o incerto. De um lado, o necessário, e a possibilidade; do outro, a probabilidade e o provável.

- Modalidade 3: Apreciação: a posição do sujeito frente a um fato de natureza apreciativa envolvendo uma avaliação.

- Modalidade 4: Pragmática (natureza intersubjetiva) determina uma relação direta entre sujeito enunciador e coenunciador (interlocutor):

a) Deôntico: (querer, ordem, permissão, desejo, sugestão, vontade, causação, possibilidade e capacidade) o sujeito do enunciado sofre uma pressão em relação à ocorrência que deve ou não se concretizar.

\section{Metodologia}

Os processos de leitura e produção de textos envolvem muitos critérios. Nosso estudo centrou-se no diálogo que o aluno fez ao ler, interpretar e criar uma moral para a fábula Hortifrutigranjeira de autoria de Luís Fernando Veríssimo. Esta atividade de linguagem foi proposta para 52 alunos do $6^{\circ}$ ano do ensino fundamental II na Escola Municipal Luiz Falcão que se localiza na Comunidade "Estiva", um povoado situado na zona rural da cidade de Caxias-MA. Dentre as 52 produções coletadas, selecionamos 13 para análise.

A metodologia utilizada se deu inicialmente com a leitura compartilhada da fábula "Hortifrutigranjeira". Logo após, para incentivar os alunos, apresentamos o título da narrativa e conversamos sobre a etimologia e o seu significado (horti, fruti, granjeira). 
Procuramos não interferir muito na interpretação deles, pois isso fazia parte dos nossos objetivos, verificar como o aluno constrói e reformula seu próprio texto a partir da interação dialógica. Feito isso, propomos aos alunos a construção da moral para esta fábula.

O que observamos durante o processo das nossas análises dessas morais construídas pelos alunos: a) Os alunos selecionaram um pré-construto a partir da narrativa da fábula, pois para o desenvolvimento dessa atividade foi dado aos alunos "um lugar" de diálogo com a narrativa; b) Eles criaram sua própria tese? Ou apenas estabeleceram uma apreciação, uma conclusão?

Primeiro, apresentamos uma categorização, uma forma didática para a realização das análises; um olhar para a tematização que acreditamos ser: <SER PEIXE>; <SER NÃO PEIXE - SER LEITE, QUEIJO, PIMENTÃO, EMBUTIDOS (PRESUNTO), ETC.> e <SER PRECONCEITO>.

A seguir, identificamos que os alunos selecionaram o pré-construto, lugar específico na narrativa em que o aluno marca um diálogo efetivo com o texto, observamos na moral construída pelos alunos valores referenciais com marcas de indefinido, relação de causa/ consequência, marcas de modalidade na construção da moral.

\section{HORTIFRUTIGRANJEIRA}

Luís Fernando Veríssimo

Era a grande a revolta na geladeira. Todos protestavam contra o peixe, que já estava pra lá de escabeche e obviamente ultrapassara todos os graus de tolerância dos seus convivas dentro daquele espaço apertado. Não era culpa do peixe, claro. Ele simplesmente ficara ali mais tempo do que o devido. Mas precisava compreender que não dava mais. Não dava.

O leite, desnaturado, era dos mais exaltados.

- Fora! - gritava espumando de raiva.

O pimentão também se agitava.

- Fora! - gritava vermelho.

Os embutidos, ensimesmados, não diziam nada, mas o presunto, que não tinha qualquer sofisticação, que era um cru, murmurava palavrões. Aquele peixe tinha que sair! As bebidas tilitavam, nervosas, e a garrafa de mineral, sempre mal-humorada - problema de gases -, gritava:

- Fora! Fora! 
O queijo não tinha moral para falar do mau cheiro de ninguém, mas o peixe já passara dos limites do socialmente aceitável. E o queijo também dizia:

- Fora!

Até o gelo, abandonando a sua conhecida atitude cool, se manifestava:

- Fora!

Nem todos, é verdade, eram tão radicais. A carne, do tipo mignon, pedia consideração para com o pobre senhor peixe.

A galinha dizia que tinha pena dele. As abobrinhas, entretidas numa conversa interminável, não prestavam atenção em mais nada, mas a manteiga e os ovos, que apesar do seu exterior aparentemente duro eram moles por dentro, achavam que o melhor era argumentar com o peixe e convencê-lo a sair, numa boa.

A verdade é que todos, com exceção dos que, como a cebola, estavam comprometidos com o prato do peixe, queriam a sua saída.

Foi quando o peixe resolveu falar.

- Quero ficar mais tempo - disse.

Ouviram-se gemidos dos outros ocupantes da geladeira. Os aspargos sacudiram a cabeça. "Madonna", exclamou a linguiça calabresa. Será que o peixe não compreendia que estava contaminando todo o ambiente? Como se não bastasse aquele inferno de viverem todos amontoados, no escuro - justamente quando a porta se fechava e precisavam da luz artificial, ela se apagava! - , ainda tinham que aguentar um peixe estragado em seu meio?

Mas o peixe insistia.

- Quero ficar - disse - para ter tempo de me recuperar.

Os outros se entreolharam. Mas como? Não havia, em toda a história das geladeiras, um único precedente para aquilo. Um prato de peixe deteriorado se recuperar com o tempo?

- Que absurdo! - disse o iogurte, azedo.

E os outros começaram a gritar, já no fim da sua paciência.

- Chega!

- Nós queremos um peixe fresco!

- Fora!

Enquanto isso, segregadas dentro de um pote, as azeitonas observavam tudo com seus olhinhos pretos.

\section{Análise da moral construída pelos alunos}

Esclarecemos que optamos em preservar a escrita do aluno, entre aspas, na íntegra, com os desvios ortográficos e gramaticais. 
Os alunos selecionaram um pré-construto na narrativa da fábula e, a partir disso, construíram a Moral. Nessa atividade, foi dado aos alunos "um lugar" de diálogo com a narrativa; eles se sentiram autores com a oportunidade de criar sua própria tese, ou apenas estabelecer uma apreciação, uma conclusão, etc. Vejamos:

\section{1. "Nunca abuse da paciência dos outros".}

Pré-construto: "E os outros começaram a gritar, já no fim da sua paciência".

No exemplo (1), na expressão ou marca "nunca abuse"/"nunca abusa", o 'nunca' marca a diferenciação da operação de localização <abuse da paciência> generalizando o enunciado, há aqui uma negação imperativa "você não abuse" em que "você se refere a todo mundo" que toma como noção <não seja peixe>, que é selecionada como uma tematização. Depois remete a 'você não deve abusar da paciência dos outros'. Assim, os alunos estabelecem não uma tese, mas uma modalização de apreciação do tipo: 'Eu acho ou concluo que não se deve ser peixe'.

Observamos que a negação é um ponto de ordenamento de oposição das ideias do aluno ao limitar sua apreciação, que se estabiliza com a relação dos verbos modais "dever" ou "poder".

\section{2. "É que ninguém é melhor que ninguém".}

Pré-construtos: "Não era culpa do peixe";

"Nem todos, é verdade, eram tão radicais".

No exemplo (2), "ninguém” estabelece a noção <não seja leite, queijo, pimentão, embutidos (presunto), etc.>. Observamos que aqui se estabelece outra tematização. O queijo, o leite, etc. são melhores que o peixe. A negação aqui é específica. Estabelece a classe, "aquele que não devem ser $<>$ ", possibilitando este espaço ser preenchido por "peixe, leite, embutidos".

Estabelece nessas criações a asserção "É que..." como mecanismo enunciativo desses contextos de opinião afırmativa.

3. "Que todos têm seus defeitos, mas só criticavam o peixe".

Pré-construtos: "Todos protestavam contra o peixe".

"O queijo não tinha moral para falar do mau cheiro de ninguém [...]". 
O aluno aqui não elabora uma moral, somente interpreta a narrativa da fábula, nesse sentido, continua no traço discreto. Questiona: somente o peixe tem defeitos? O termo "Todos" se apresenta em sentido de totalidade e traz a noção <ter $><$ não ter $>$ seus próprios defeitos. A marca 'todos' denota um conjunto de ocorrências sem selecionar este ou aquele elemento; é uma operação de varredura que opera sobre cada elemento de um conjunto ou sobre a totalidade dele. Em "mas só criticavam o peixe", o valor temporal, pretérito imperfeito, não finaliza a ação no passado, nota-se a marca de continuidade e imperfectividade em que o peixe está sendo penalizado, porque na leitura do aluno, todo mundo tem defeitos, até o peixe.

4. "Todos temos nosso espaço no qual devemos ser prevenidos para não causar intolerância a quem está ao nosso lado".

Pré-construto: "[...] e obviamente ultrapassara todos os graus de tolerância dos convivas dentro daquele espaço apertado".

O aluno que criou a moral acima estabelece uma generalização da interpretação da narrativa da fábula. Ao se referir a "todos", "temos", "nosso" estabelece um diálogo geral com "todo mundo" ou "todas as pessoas", ou seja, convoca a todos. O termo 'todos' marca uma operação de determinação por varredura que opera sobre a totalidade da ocorrência.

O verbo modal "dever" traz uma apreciação da noção <ser prevenido> estabelecendo uma relação de um lado de finalidade, causalidade e consequência; de outro lado, o certo, o provável.

A expressão do mecanismo enunciativo de "a quem" faz uma relação de cotexto com "ao nosso lado", criando um espaço de aproximação com todos.

5. "Esse texto relata que, acima de tudo, as pessoas têm muito preconceito, não devemos ser assim, somos todos iguais não importa sua cor, nem raça, somos todos irmãos".

Pré-construto: o preconceito "Nem todos, é verdade, eram tão radicais".

"Acima de tudo" para esse aluno a tematização da narrativa refere-se ao preconceito e está em um alto grau. Em, "não devemos ser assim" observamos mais uma vez a escolha pela marca da negação, operação de diferenciação 'as pessoas têm preconceito' e pela modalização da possibilidade do verbo 'dever'. Então, em "somos todos iguais", "somos todos irmãos" o determinante 'todos' opera a varredura nas ocorrências sobre a totalidade, $<$ todos iguais> QLT, e <todos irmãos> QNT. O aluno discretiza quando amplia do particular para a generalização com o uso de "tudo" e "todos", deixando em aberto um fato discreto e singular. 
6. "Se não souber o que falar é melhor ficar calado".

Pré-construto: o aluno retira do final da narrativa da fábula "Enquanto isso, segregadas dentro de um pote, as azeitonas observavam tudo com seus olhinhos pretos".

O condicional foi marcado pelo "se", talvez retomando o pré-construto do final da narrativa da fábula: "Enquanto isso, segregadas dentro de um pote, as azeitonas observavam tudo com seus olhinhos pretos".

7. "Não devemos criticar o próximo, porque às vezes ele não tem culpa do seu estado".

Pré-construto: "Não era culpa do peixe, claro".

O artigo definido é uma marca de determinação por flechagem, pois o pré-construído pela existência seria: "Há um próximo que foi criticado". O aluno toma a posição da noção de <ser peixes, pois o peixe não tem culpa de seu estado (apodrecido/mal cheiroso). Observamos no cotexto 'Não devemos criticar' e 'não tem culpa' ambos marcados pela negação e pela modalização dos verbos 'dever' e 'ter'. Na primeira, o aluno referiu a "nós", se incluindo nessa discretização, e na segunda chama o "ele", a noção <ser peixe>. Fica evidente a defesa pelo peixe, que embora esteja no lugar 'errado', o aluno buscou justificar com a explicação 'porque às vezes ele não tem culpa do seu estado'. Nota-se que 'às vezes' se opõe a 'sempre' que ressalta a mudança de estado do peixe que pode alternar.

\section{8. "O peixe não estava preocupado".}

Pré-construto: "Foi quando o peixe resolveu falar.

- Quero ficar mais tempo [...]".

"O peixe <que é mal cheiroso> não se preocupa" operação de diferenciação e especificação do peixe. $\mathrm{O}$ artigo definido marca uma operação de flechagem, pois "Há um peixe". Então, a construção da moral recai sobre a noção de <ser peixe>. Não há preocupação com as classes de embutidos, lacticínios, carnes, etc., deixando-os implícitos. A negação marca a oposição 'o peixe estava preocupado' nesta localização de aspectualidade, naquele momento passado o peixe mal cheiroso se preocupou. Agora, não tem preocupação com nada e nem com ninguém.

9. "Se tem um peixe podre num cardume se torna todos podres e se tem uma pessoa com o caráter ruim dentro da comunidade contagia os outros".

Pré-construtos: "mas o peixe já passara dos limites do socialmente aceitável".

" [...] dentro daquele espaço apertado".

"Será que o peixe não compreendia que estava contaminando todo o ambiente?" 
Nessa construção de tese da Moral, fizemos uma análise em dois momentos, a seguir:

a) "Se tem um peixe podre num cardume se torna todos podres".

b) "Se tem uma pessoa com o caráter ruim dentro da comunidade contagia os outros".

Ambas são introduzidas pelo uso de um condicional (se), juntamente com o verbo modal "ter", isso conduziu o aluno a estabelecer comparações entre "um peixe" e "uma pessoa"; o artigo indefinido opera como um determinante de extração, o sujeito enunciador estabelece um valor específico dos nominais discretos peixe e pessoa com predominância de QNT: "um peixe podre" e "uma pessoa de caráter ruim", portanto, os nominais estão qualificados (QLT) pelo cotexto dos termos 'podre' e 'ruim' operando valores de especificação; em "num cardume" 'num' é em+um e "dentro da comunidade". Percebe-se o jogo enunciativo de QNT/QLT, que são espaços de construções, ou seja, de localização. O aluno remete, por uma questão de intertextualidade, ao ditado popular "Uma ovelha ruim põe o rebanho a perder". Nesses lugares se (por possibilidade) for colocado: Umas pessoas ruins QNT/QLT ou Um peixe podre pela relação causa e consequência "todos os outros" tanto peixes, como os outros itens da geladeira, como todas as pessoas da comunidade serão "contagiados" ou "contaminados".

10. "Que ele queria um peixe fresco".

Pré-construto: "Nós queremos um peixe fresco".

Na construção (10), há um diálogo do aluno com o autor ou sujeito da enunciação da fábula, quando instaura "que ele queria". Questionamos "Quem queria?" O aluno responde, "ele". E quem é o "ele"?

O verbo "querer" traz uma apreciação do tipo de peixe e de forma bem sintética "um peixe fresco". "Um peixe fresco", 'um', determinante de extração QNT/QLT, resolveria toda a discussão dentro da geladeira. "um peixe fresco" não incomodaria os outros, não seria mal cheiroso e agradaria a todos. Seria a solução do problema.

Observamos que a Moral construída pelo aluno chama a atenção pela resolução ou fechamento.

11. "Queremos um peixe fresco".

Pré-construto: "Nós queremos um peixe fresco". 
O aluno se inclui quando diz: "nós queremos" na noção <queredor> <querer> <querível>, ou seja, todas as pessoas e todos os presentes na geladeira não querem o peixe que é mal cheiroso, "todos" queremos "um peixe fresco". Observamos que o aluno estabeleceu uma resposta ao título da fábula "A solução". Essa sua resposta é a possibilidade de se querer <um peixe fresco>, assim, o artigo indefinido marca a extração do valor não genérico, só assim estaria resolvido o problema.

12. "A moral do texto que eu acredito é que apesar os alimentos estava com preconceito com o peixe por causa do seu mal cheiro".

Pré-construto: "Não era culpa do peixe".

O aluno olha para a problemática do preconceito ou pelas opiniões do queijo, do leite, do pimentão, dos embutidos, porque o peixe não era bem-vindo por causa do seu mau cheiro. O preconceito não é um sentimento bom, é um sentimento hostil em relação ao peixe. A noção <ser peixe> foi defendida pelo aluno, que observou que os outros alimentos assumiram uma consequência negativa e generalizada em relação à experiência do peixe. O aluno é o sujeito que dialoga e diz: "eu acredito", "é que" para explicar sua opinião.

0 artigo definido 'os' e 'o' determinam os nominais alimentos e peixe que tem traços discretos e qualifica - QLT em predominância na ocorrência marcado pelas operações de flechagem, pois "Há uns alimentos" e "Há um peixe mal cheiroso".

\section{3. "Queríamos um peixe fresco:".}

Pré-construto: "Nós queremos um peixe fresco".

Esse aluno coloca o tempo do verbo 'querer' no pretérito imperfeito diferente do tempo selecionado do exemplo (1I) que o aluno colocou no presente do indicativo. Essas escolhas nos revelam diferentes expectativas dos alunos. No primeiro, uma questão aspectual é apresentada pela continuidade da ação (queríamos) de querer um peixe fresco. No segundo, em "queremos", a forma do presente revela um desejo generalizado e confirmado por todos.

Cabe ressaltar que a pesquisa foi aprovada, em 23 de maio de 2018, no Comitê de Ética em Pesquisa da Universidade Federal de São Carlos (UFSCar) - CAAE-81125317.1.0000.5504 Número do parecer: 2.671.288.

\section{Considerações finais}

Quando se propõe uma atividade de linguagem, por exemplo, o que analisamos neste artigo, é possível verificar que os alunos se preocuparam em ler e interpretar e, muitas vezes, apenas estabelecem uma conclusão dessa interpretação, como podemos observar em (3), (4), o educando utilizou verbos modais como: dever, poder, ter, presentes em (1), 
(4), (5), (7). Notamos também várias marcas de modalização: a apreciação, como em (1), (2), (10), (11), a negação (2), (5), (7), (8), (12), a de possibilidade (5), relação de finalidade, causalidade e consequência (4), aspectualidade (8), (13), marcas de condicional (6), (9) e ainda, uma marca de intertextualidade (9).

As operações de determinação QNT e QLT, presentes na produção textual, foram analisadas como noções de definitude e de indefinitude que envolveram as operações de extração, de flechagem (artigos indefinidos 'um', 'uma', 'umas' e artigos definidos 'o', 'a', 'os', e 'as'), os pronomes indefinidos apresentaram como varredura (parcours), principalmente 'todo', 'todos, 'toda' e 'todas'. Estabelecemos a relação com os nominais das categorias dos nomes enumeráveis e não enumeráveis, quantificáveis, não quantificáveis no que decorrem das propriedades primitivas dos traços discreto, denso e compacto.

Percebe-se que o aluno fica muito preocupado em interpretar a narrativa, de modo geral, e consegue concluir apoiado nessa interpretação, alguns conseguem avançar e deixam sua criatividade aflorar, sua escrita passa pelo processo de particularização para a generalização dando início à construção de uma tese (dissertação) que se valida com a verdade. $\mathrm{O}$ ensino da língua materna deve proporcionar aos educandos atividades de linguagem que propiciem reflexões e, por sua vez, promovam o desenvolvimento linguístico-cognitivo nos alunos.

\section{REFERÊNCIAS}

CULIOLI, A. Notes du Seminaire de D.E.A.: 1983-1984. Poitiers: Départament de Recherches Linguistiques (D.R.L.): Université de Paris 7, p. 1-46, 1985.

CULIOLI, A. Pour une linguistique de l'énonciation. Paris: Ophrys, 1990, t. 1.

CULIOLI, A. Pour une linguistique de l'énonciation. Paris: Ophrys, 1999a, t. 2.

CULIOLI, A. Pour une linguistique de l'énonciation. Paris: Ophrys, 1999b, t. 3.

CULIOLI, A. Pour une linguistique de l'énonciation: Tours et Détours, Paris: Limoges, Lambert-Lucas, 2018, t. 4.

ONOFRE, M. B. Do nome à noção: do enfoque estático ao dinâmico. Versão BETA: sob o signo da Palavra, São Carlos, ano 2, n. 22, p. 57-67, jul. 2003.

VALENTIM, H. T. Um estudo semântico-enunciativo de predicados subjectivos do português. 2004. Tese (Doutorado em Linguística) - Universidade Nova de Lisboa, Lisboa, 2004.

VERÍSSIMO, L. F. Hortifrutigranjeira. 1988. Disponível em: http://linguagensecriatividade. blogspot.com/2009/06/fabula-luis-fernando-verissimo.html. Acesso em: 29 ago. 2020. 